\title{
Differential Responses of Colorectal Cancer Cell Lines to Enterococcus faecalis' Strains Isolated from Healthy Donors and Colorectal Cancer Patients
}

\author{
Carolina Vieira De Almeida ${ }^{1}\left(\mathbb{D}\right.$, Matteo Lulli $^{2}{ }^{(0)}$, Vincenzo di Pilato ${ }^{3}{ }^{\mathbb{D}}$, Nicola Schiavone $^{2}$, \\ Edda Russo $^{3}{ }^{\circledR}$, Giulia Nannini ${ }^{3}$, Simone Baldi ${ }^{3}$, Rossella Borrelli ${ }^{3}$, Gianluca Bartolucci ${ }^{4}(\mathbb{D}$, \\ Marta Menicatti ${ }^{4}$, Antonio Taddei ${ }^{1}$ (D), Maria Novella Ringressi ${ }^{1}$, Elena Niccolai ${ }^{3} \mathbb{D}$, \\ Domenico Prisco $^{3}$, Gian Maria Rossolini ${ }^{3,5}$ and Amedeo Amedei ${ }^{3,6, *(D)}$ \\ 1 Department of Surgery and Translational Medicine, University of Florence, 50134 Florence, Italy; \\ almeida.cv@gmail.com (C.V.D.A.); antonio.taddei@unifi.it (A.T.); marianovella.ringressi@unifi.it (M.N.R.) \\ 2 Department of Experimental and Clinical Biomedical Sciences "Mario Serio", University of Florence, \\ 50134 Florence, Italy; matteo.lulli@unifi.it (M.L.); nicola.schiavone@unifi.it (N.S.) \\ 3 Department of Experimental and Clinical Medicine, University of Florence, 50134 Florence, Italy; \\ vincenzo.dipilato@unifi.it (V.d.P.); edda.russo@unifi.it (E.R.); giulia.nannini@unifi.it (G.N.); \\ simone.baldi1@stud.unifi.it (S.B.); rossella.borrelli92@gmail.com (R.B.); elena.niccolai@unifi.it (E.N.); \\ domenico.prisco@unifi.it (D.P.); gianmaria.rossolini@unifi.it (G.M.R.) \\ 4 Department of Neurosciences, Psychology, Drug Research and Child Health Section of Pharmaceutical and \\ Nutraceutical Sciences University of Florence, 50139 Florence, Italy; gianluca.bartolucci@unifi.it (G.B.); \\ marta.menicatti@unifi.it (M.M.) \\ 5 Department of Microbiology and Virology Unit, Florence Careggi University Hospital, 50134 Florence, Italy \\ 6 Department of Biomedicine, Azienda Ospedaliera Universitaria Careggi (AOUC), 50134 Florence, Italy \\ * Correspondence: amedeo.amedei@unifi.it; Tel.: +5-52-758-330
}

Received: 19 February 2019; Accepted: 15 March 2019; Published: 20 March 2019

Abstract: The metabolites produced by the host's gut microbiota have an important role in the maintenance of intestinal homeostasis, but can also act as toxins and induce DNA damage in colorectal epithelial cells increasing the colorectal cancer (CRC) chance. In this scenario, the impact of some of the components of the natural human gastrointestinal microbiota, such as Enterococcus faecalis (E. faecalis), at the onset of CRC progression remains controversial. Since under dysbiotic conditions it could turn into a pathogen, the aim of this study was to compare the effect of E. faecalis' strains (isolated from CRC patients and healthy subjects' stools) on the proliferation of different colorectal cells lines. First, we isolated and genotyping characterized the Enterococcus faecalis' strains. Then, we analyzed the proliferation index (by 3-(4,5-Dimethylthiazol-2-yl)-2,5-Diphenyltetrazolium Bromide (MTT) assay) of three tumor and one normal intestinal cell lines, previously exposed to E. faecalis strains pre-cultured medium. Stool samples of CRC patients demonstrated a reduced frequency of $E$. faecalis compared to healthy subjects. In addition, the secreted metabolites of E. faecalis' strains, isolated from healthy donors, decreased the human ileocecal adenocarcinoma cell line HCT-8 and human colon carcinoma cell line HCT-116 cell proliferation without effects on human colorectal adenocarcinoma cell line SW620 and on normal human diploid cell line CLR-1790. Notably, the metabolites of the strains isolated from CRC patients did not influence the cell growth of CRC cell lines. Our results demonstrated a new point of view in the investigation of E. faecalis' role in CRC development, which raises awareness of the importance of not only associating the presence/absence of a unique microorganism, but also in defining the specific characteristics of the different investigated strains.

Keywords: colorectal cancer; Enterococcus faecalis; bacterial metabolites; gut microbiota; tumor cell lines 


\section{Introduction}

Colorectal cancer (CRC) is one of the most commonly diagnosed cancers among both men and women worldwide, being the third most frequent in many high-income countries, with an estimated more than 100,000 new cases expected in 2018 [1]. The CRC incidence in low-income countries is closely related with differences in lifestyle [2,3], with only $15 \%$ of cases having a familial feature, whereas sporadic forms represent 85\% [4]. Environmental factors, such as smoking, alcoholism, obesity, sedentary lifestyle, consumption of red meat, high-fat diet, and inadequate fiber intake, are closely involved in the CRC onset and progression [5]. All these risk factors also have a modulating role on the host gut microbiota (GM) composition, whose effects on CRC progression/protection have been investigated during the last years [6,7]. The gut microbiota, a natural defensive barrier to infections, is involved in several physiological functions and plays a key role in maintaining the gut homeostasis [8]. The GM members can modulate the mucosal immune system, as well as directly change the expression of some host genes associated with nutrient uptake, metabolism, angiogenesis, and mucosal barrier functions $[9,10]$.

The GM's protective role against intestinal diseases is closely linked with its ability to ferment a range of dietary substances that are not completely digested and absorbed in the small intestine. The microbial carbohydrate fermentation, for example, produces short chain fatty acids (SCFAs), such as acetic, propionic, and butyric, which can be further metabolized by mammalian cells for energy, thus having beneficial effects. On the other hand, bacterial transformation of dietary components and other chemicals in the intestinal lumen is associated with the production of carcinogenic agents, whose damaging effects on colonic mucosal cells can influence cancer development [11]. In fact, approximately $20 \%$ of cancers are associated with microbes [10], especially CRC [12-14], where a dynamic crosstalk exists between intestinal epithelial cells, the microbes (that colonize their apical surface), and the surrounding local immune cells [15], which, in turn, have a key role in CRC progression, especially T cells [16].

While some GM members (Streptococcus bovis, Bacteroides, Clostridia, and Helicobacter pylori) have an evident role on cancer promotion [17] and others play protective roles (Lactobacillus spp. and Bifidobacterium spp.) [18], for the symbiotic lactic acid bacteria (LAB), Enterococcus faecalis (E. faecalis), a controversial role in CRC has been hypothesized. This Firmicutes phylum member belonging to the Enterococcaceae family, even if used as a probiotic product $[19,20]$ due to its great ability to confer beneficial effects on human health by their fermented products [21], has also been regarded as being possibly involved in CRC development, given its ability to damage the deoxyribonucleic acid (DNA) of colonic epithelial cells [22]. Moreover, previous studies have demonstrated that the feces of CRC patients showed increased concentrations of E. faecalis, strengthening its role as cancer promoter $[23,24]$.

Among intestinal Enterococci, E. faecalis is the most prevalent cultured species found in human feces $\left(10^{5}\right.$ to $10^{7}$ Colony Forming Unit (CFU) $\left./ \mathrm{g}\right)$, followed by E. faecium $\left(10^{4}\right.$ to $\left.10^{5} \mathrm{CFU} / \mathrm{g}\right)$, but these proportions change with the host's geographical location and especially with diet [25]. E. faecalis is one of the first colonizers of the human gastrointestinal tract and it has a major impact on intestinal immune development in the very early life stages [26]. In newborns, it plays a protective role, regulating the colonic homeostasis during development by suppressing pathogen-mediated inflammatory responses in human intestinal epithelial cells, inducing interleukin (IL)-10 expression [27] and attenuating proinflammatory cytokine secretions, especially IL-8 [28].

Aiming to verify whether E. faecalis strains isolated from CRC patients' feces have substantial differences with those isolated from healthy donors' samples, we recruited nine CRC Italian patients and nine healthy donors matched by age. Our results pointed out significant genotyping differences among all the E. faecalis strains, mainly regarding the genes of adhesion and virulence factors. Consequently, we analyzed the effect of the metabolites of the different isolated strains on three CRC cell lines' proliferation (and a normal colon cell line), demonstrating an antiproliferative role only for those strains isolated from healthy donors. 


\section{Material and Methods}

\subsection{Ethical Statement}

The Local Ethics Committee (Prot. 2010/0012462) approved the study. Institutional Ethics Committee Statement: All procedures involving the cells of healthy donors were done according to the Declaration of Helsinki and approved by the local Ethics Committee by the AOUC Careggi Institutional Review Board (Prot. 2010/0012462).

\subsection{CRC Patients and Healthy Donors}

Overall, nine patients with CRC and nine healthy donors were enrolled at Careggi University Hospital (Florence, Italy) (Table 1) between April and May 2016. Exclusion criteria included antibiotic intake and use of probiotics/culture milk 2 months before and within the study. All the participants provided an informed written consent prior to enrolment, in compliance with national legislation and the Code of Ethical Principles for Medical Research Involving Human Subjects of the World Medical Association (Declaration of Helsinki).

Table 1. CRC patient and healthy donors' characteristics.

\begin{tabular}{|c|c|c|}
\hline $\begin{array}{c}\text { Donors } \\
\text { (Healthy-HD Colon } \\
\text { Cancer-CC) }\end{array}$ & $\begin{array}{c}\text { Age/Gender } \\
\left(\& / \sigma^{\top}\right)\end{array}$ & Histotype/Stage \\
\hline HD01 & 57 우 & $\mathrm{n} / \mathrm{a}$ \\
\hline HD02 & $600^{x}$ & $\mathrm{n} / \mathrm{a}$ \\
\hline HD03 & $560^{x}$ & $\mathrm{n} / \mathrm{a}$ \\
\hline HD04 & 53 우 & $\mathrm{n} / \mathrm{a}$ \\
\hline HD05 & 68 웅 & $\mathrm{n} / \mathrm{a}$ \\
\hline HD06 & $650^{7}$ & $\mathrm{n} / \mathrm{a}$ \\
\hline HD07 & 68 우 & $\mathrm{n} / \mathrm{a}$ \\
\hline HD08 & $480^{7}$ & $\mathrm{n} / \mathrm{a}$ \\
\hline HD09 & $520^{x}$ & $\mathrm{n} / \mathrm{a}$ \\
\hline $\mathrm{CC} 01$ & $780^{7}$ & $\begin{array}{c}\text { Colorectal adenocarcinoma with moderate } \\
\text { differentiation ( } \mathrm{pT} 3 \mathrm{~N} 0)\end{array}$ \\
\hline $\mathrm{CC02}$ & $790^{7}$ & $\begin{array}{c}\text { Colorectal adenocarcinoma with moderate } \\
\text { differentiation ( } \mathrm{pT} 3 \mathrm{~N} 0)\end{array}$ \\
\hline $\mathrm{CCO3}$ & 68 웅 & $\begin{array}{c}\text { Colorectal adenocarcinoma with moderate } \\
\text { differentiation (pT2N0) }\end{array}$ \\
\hline $\mathrm{CC04}$ & $780^{7}$ & Colon intramucosal adenocarcinoma (pT2N0) \\
\hline CC05 & $400^{7}$ & $\begin{array}{c}\text { Colorectal adenocarcinoma with moderate } \\
\text { differentiation (pT3aN1aMx) }\end{array}$ \\
\hline $\mathrm{CC06}$ & $780^{7}$ & $\begin{array}{c}\text { Colorectal adenocarcinoma with moderate } \\
\text { differentiation (pT1N0) }\end{array}$ \\
\hline $\mathrm{CC07}$ & 81 우 & $\begin{array}{c}\text { Colorectal adenocarcinoma with moderate } \\
\text { differentiation (pT2N0Mx) }\end{array}$ \\
\hline $\mathrm{CC08}$ & $620^{7}$ & $\begin{array}{c}\text { Colorectal adenocarcinoma with moderate } \\
\text { differentiation (pT2N0Mx) }\end{array}$ \\
\hline CC09 & $630^{7}$ & $\begin{array}{c}\text { Colorectal adenocarcinoma with moderate } \\
\text { differentiation (pT3N0Mx) }\end{array}$ \\
\hline
\end{tabular}

CRC: colorectal cancer; : : female; $0^{n}:$ male; $n /$ a: not available.

\subsection{Isolation and Genotyping of Enterococcus faecalis}

To isolate the E. faecalis strains, we resuspended $0.25 \mathrm{~g}$ of feces in $250 \mu \mathrm{L}$ of sterile saline $(\mathrm{NaCl}$ $0.9 \%$ ). From this solution, we plated $50 \mu \mathrm{L}$ onto Columbia CNA (colistin, nalidixic acid) blood agar with crystal violet (CV) (CNA-CV Agar) with 5\% sheep blood (Sh) enrichment (CNA-CVSh) (Becton, Dickinson and Company, Franklin Lakes, NJ, USA) and incubated it at $37^{\circ} \mathrm{C}$ for $30 \mathrm{~h}$. Then, we isolated single colonies ( $\pm 0.032 \mathrm{CFU} / \mathrm{mg}$ of stool) and cultivated them onto Columbia with $5 \%$ sheep blood 
(COS) medium (Biomerieux, Grassina, FI, Italy) for $24 \mathrm{~h}$ at $37^{\circ} \mathrm{C}$. To identify the species' level of putative Enterococci colonies, we performed a Matrix Assisted Laser Desorption/Ionization Time of Flight MALDI-TOF assay (Vitek MS, BioMérieux Inc., Marcy l'Etoile, France). The confirmed E. faecalis colonies were stored at $-80{ }^{\circ} \mathrm{C}$ in brain heart infusion broth medium (BHI) (Oxoid, Altrincham, Cheshire, UK) with $10 \%$ glycerol added. When necessary, we grew these strains on COS medium at $37^{\circ} \mathrm{C}$ for $24 \mathrm{~h}$ before performing different experiments.

To evaluate the clonal diversity of the isolated E. faecalis colonies $(n=16)$, we performed a Random Amplified Polymorphic DNA- Polymerase Chain Reaction (RAPD)-PCR assay, as previously described by Martin et al. 2005 [29]. RAPD-PCR was performed on cell lysates obtained by resuspension of single bacterial colonies in $300 \mu \mathrm{L}$ of Tris- Ethylenediaminetetraacetic acid (TE) buffer, incubation for $15 \mathrm{~min} 95^{\circ} \mathrm{C}$, and clarification through centrifugation for $5 \mathrm{~min}$ at $13,000 \mathrm{rpm}$.

Quantitative detection of E. faecalis was performed by q-PCR on total DNA extracted from subjects' feces using the DNeasy Power Lyzer Power Soil DNA isolation Kit (MoBio-QIAgen, Valencia, CA, USA). We used a species-specific primer set for the detection of E. faecalis and universal primers for the detection of the total bacterial loads to target the 16S rRNA gene, as previously described by Sedgley et al. [30]. The PCR thermal conditions were: $3 \mathrm{~min}$ for the initial enzyme activation/DNA denaturing step at $95^{\circ} \mathrm{C}$ followed by 44 consecutive cycles at $95^{\circ} \mathrm{C}$ for $20 \mathrm{~s} ;\left(57^{\circ} \mathrm{C}\right.$ E16S) $\left(53^{\circ} \mathrm{C}\right.$ for $\mathrm{U} 16 \mathrm{~S})$ for $45 \mathrm{~s} ; 60^{\circ} \mathrm{C}$ for $5 \mathrm{~s}$.

As previously described, whole genome sequencing was performed [31] on selected E. faecalis to include all the different clonal profiles, identified according to RAPD-PCR results $(n=8)$. We investigated the clonal relatedness by the determination of: (i) The Multilocus sequence typing (MLST) profile through the MLST 1.8 tool [32] using the assembled whole genome sequences as the input; (ii) the core genome SNP phylogeny, through the CSI Phylogeny 1.4 tool [33], using default parameters and the raw sequence reads as the input. We generated the phylogenetic trees, using the E. faecalis $\mathrm{ATCC}^{\circledR} 29212^{\mathrm{TM}}$ genome (GenBank acc. no. NZ_CP008816.1) as a reference. Identification of prophage sequences was carried out using PHAge Search Tool Enhanced Release (PHASTER) [34]. The presence of virulence factors and antibiotic resistance genes was assessed using the VirulenceFinder 1.5 and the ResFinder 3.0 tools [35], respectively. We performed the sequence comparison by using the Basic Local Alignment Search Tool (BLASTN) software and the nr or wgs databases [36]. Draft genomes of sequenced strains were deposited at National Center for Biotechnology Information (NCBI) as Whole Genome Sequence WGS projects (accession numbers to be assigned).

\subsection{Secreted Metabolites}

To obtain pre-fermented medium, we used the protocol previously described by Grootaert et al. [37] with some modifications. Briefly, the E. faecalis strains were cultivated in $5 \mathrm{~mL}$ of BHI medium at 37 ${ }^{\circ} \mathrm{C}$. After $10 \mathrm{~h}$, an equal number of cells $\left(3 \times 10^{8} \mathrm{CFU} / \mathrm{mL}\right)$ was centrifuged $(5 \mathrm{~min}, 13,000 \mathrm{rpm})$ and washed with $1 \mathrm{~mL}$ of PBS. The pellets were suspended in $5 \mathrm{~mL}$ of Roswell Park Memorial Institute (RPMI) 1640 medium (Thermo Fisher Scientific Inc., Waltham, MA, USA) without antibiotics or fetal bovine serum (FBS) and incubated at $37^{\circ} \mathrm{C}$ for $3 \mathrm{~h}$. Thereafter, the suspension was centrifuged ( $5 \mathrm{~min}$, $4000 \mathrm{rcf}$ ) and the supernatant was sterilized with a $0.22 \mathrm{~mm}$ filter (Millipore, Billerica, MA, USA) and retained as the pre-fermented medium. We used the commercial ATCC29212 strain as a control (ATCC, Manassas, VA, USA).

\subsection{Gas Chromatography Mass Spectrometry (GC-MS) Analysis of SCFAs}

Methanol and tert-butyl methyl ether (Chromasolv grade), sodium bicarbonate and hydrochloric acid (reagent grade), $\left(2 \mathrm{H}_{3}\right)$ Acetic, $\left(2 \mathrm{H}_{3}\right)$ Propionic, $\left(2 \mathrm{H}_{7}\right)$ iso-Butyric and $\left(2 \mathrm{H}_{9}\right)$ iso-Valeric (used as internal standards (ISTDs)), acetic acid, propionic acid, butyric acid, isobutyric acid, valeric acid, and isovaleric acid (analytical standards grade) were purchased by Sigma-Aldrich (Milan, Italy). MilliQ water $18 \mathrm{M} \Omega$ was obtained from Millipore's Simplicity system (Milan, Italy). The SCFAs' analysis was 
performed by an Agilent GC-MS system composed with a 5971 single quadrupole mass spectrometer, 5890 gas-chromatograph, and 7673 autosampler.

The SCFAs in the samples (Table S2) were analyzed as free acid form using a SupelcoNukol column, with a $30 \mathrm{~m}$ length, $0.25 \mathrm{~mm}$ internal diameter, and $0.25 \mu \mathrm{m}$ of film thickness with the temperatures program as follows: Initial temperature of $40^{\circ} \mathrm{C}$ was held for $1 \mathrm{~min}$, then it was increased to $150{ }^{\circ} \mathrm{C}$ at $30^{\circ} \mathrm{C} / \mathrm{min}$, and finally increased to $220^{\circ} \mathrm{C}$ at $20^{\circ} \mathrm{C} / \mathrm{min} .1 \mu \mathrm{L}$ aliquot of the extracted sample was injected in splitless mode (splitless time $1 \mathrm{~min}$ ) at $250^{\circ} \mathrm{C}$, while the transfer line temperature was $280^{\circ} \mathrm{C}$. The carrier flow rate was maintained at $1 \mathrm{~mL} / \mathrm{min}$.

\subsection{Cell Lines}

The used cell lines were purchased from the American Type Culture Collection (ATCC, Manassas, VA, USA). Since primary and metastatic tumor cells have different metabolic, genetic, epigenetic, and morphological characteristics, we decided that it was more appropriate to evaluate the effect of E. faecalis metabolites in different CRC cell lines. In detail, we chose HCT-116 and HCT-8 as the primary tumors' model and SW-620 as a lymphonode metastasis model. The embryo colonic cell line, CLR-1790, was used as the non-tumor control. The culture conditions of each cell line are reported in Table 2.

Table 2. Cell lines' features and culture conditions.

\begin{tabular}{|c|c|c|}
\hline Cell Line & Medium & Other Information \\
\hline HCT-116 & $\begin{array}{c}\mathrm{DMEM}+2 \mathrm{mM} \text { L-Glutamine }+100 \mathrm{U} / \mathrm{mL} \\
\text { Penicillin }+100 \mu \mathrm{g} / \mathrm{mL} \text { Streptomycin }+10 \% \\
\text { FBS }\end{array}$ & $\begin{array}{c}\left.\text { (CCL-247 }{ }^{\mathrm{TM}}\right) \mathrm{ATCC}^{\circledR}, \text { Manassas, VA, USA. } \\
\text { Colon; colorectal carcinoma, male, } \\
\text { epithelial, primary tumor. }\end{array}$ \\
\hline HCT-8 & $\begin{array}{c}\text { DMEM + } 2 \text { mM L-Glutamine + } 100 \mathrm{U} / \mathrm{mL} \\
\text { Penicillin }+100 \mu \mathrm{g} / \mathrm{mL} \text { Streptomycin }+ \\
10 \% \text { FBS }\end{array}$ & $\begin{array}{l}\left(\mathrm{CCL}-244^{\mathrm{TM}}\right) \mathrm{ATCC}^{\circledR}, \text { Manassas, VA, USA. } \\
\text { Colon; ileocecal colorectal adenocarcinoma; } \\
\text { primary tumor, epithelial. }\end{array}$ \\
\hline SW-620 & $\begin{array}{c}\text { DMEM + } 2 \text { mM L-Glutamine + } 100 \mathrm{U} / \mathrm{mL} \\
\text { Penicillin }+100 \mu \mathrm{g} / \mathrm{mL} \text { Streptomycin }+ \\
10 \% \text { FBS }\end{array}$ & $\begin{array}{c}\left(\text { CCL-227 }^{\mathrm{TM}}\right) \mathrm{ATCC}^{\circledR}, \text { Manassas, VA, USA. } \\
\text { Colon; derived from metastatic site: lymph } \\
\text { node; Dukes' type C, colorectal } \\
\text { adenocarcinoma; male; epithelial }\end{array}$ \\
\hline CLR-1790 & $\begin{array}{c}\text { 50\% DMEM + 50\% Ham's F12 Nutrient Mixture } \\
+2 \mathrm{mM} \text { L-Glutamine + } 100 \mathrm{U} / \mathrm{mL} \text { Penicillin }+ \\
100 \mu \mathrm{g} / \mathrm{mL} \text { Streptomycin }+10 \% \text { FBS }\end{array}$ & $\begin{array}{c}(\mathrm{CCD} 841 \mathrm{CoN}) \mathrm{ATCC}^{\circledR}, \text { Manassas, VA, } \\
\text { USA. Colon; normal; } 21 \text { weeks gestation } \\
\text { fetus; epithelial. }\end{array}$ \\
\hline
\end{tabular}

HCT-8: Human ileocecal adenocarcinoma cell line; HCT-116: Human colon carcinoma cell line; SW-620:human colorectal adenocarcinoma cell line; CLR-1790: normal human diploid cell line; DMEM: Dulbecco's Modified Eagle Medium; FBS: Fetal Bovine Serum.

\subsection{Treatment of Cell Lines with Pre-Fermented Medium and MTT Assay}

The human HCT-116, HCT-8, and SW-620 colon cancer cells, and the normal intestinal CLR-1790 cells were plated on flat-bottomed 96-well culture plates $\left(5 \times 10^{3}\right.$ cells/well) and incubated with their respective culture medium for $24 \mathrm{~h}$ at $37^{\circ} \mathrm{C}$ under $5 \% \mathrm{CO}_{2}$ tension. After, we added the pre-fermented medium in a proportion of 1:5 (pre-fermented medium:culture medium). We used RPMI as the control. The effect of the E. faecalis secreted metabolites on cell proliferation was determined using the MTT assay [38] after $72 \mathrm{~h}$ of culture. Absorbance was measured at $595 \mathrm{~nm}$ using the iMark microplate reader (Biorad, Hercules, CA, USA) for the cell viability calculation while the absorbance of the controls was set as $100 \%$ of cell viability $(\%$ of cell viability $=($ sample O.D. $/$ control O.D. $) \times 100)$. Analyses were performed in three independent experiments, with four experimental replicates for each experimental point $(\%$ of cell viability $=($ sample absorbance $/$ control absorbance $) \times 100)$. 


\subsection{Ki67 Immunofluorescence Analysis}

Cells were grown on glass coverslips, washed twice with $1 \mathrm{~mL}$ of cold PBS, and fixed for $20 \mathrm{~min}$ in 3.7\% paraformaldehyde in PBS and permeabilized with $0.3 \%$ Triton X-100 in PBS for $5 \mathrm{~min}$. Cells were incubated in blocking buffer (5\% FBS and 0.3\% Triton X-100 in PBS) for $1 \mathrm{~h}$ at room temperature. Then, the cells were incubated overnight at $4{ }^{\circ} \mathrm{C}$ with ki67 antibody (Santa Cruz Biotechnology, Dallas, TX, USA) and successively for $1 \mathrm{~h}$ with the anti-mouse DyLightTM 488 secondary antibody (KPL, Gaithersburg, MD, USA) at room temperature. After staining of the nuclei with Hoechst 33242 dye (4',6-diamidino-2-phenylindole; Life Technologies, Carlsbad, CA, USA), the cells were dried, mounted onto glass slides with ProLong Diamond AntifadeMountant (Thermo Fisher Scientific, Waltham, MA, USA), and examined with a confocal microscopy using a Nikon Eclipse TE2000-U (Nikon, Tokyo, Japan). A single composite image was obtained by superimposition of 6 optical sections for each sample observed. The collected images were analyzed by ImageJ software [39]. All the experiments have were repeated three times.

\subsection{Statistical Analysis}

Differences in the proliferation index for each experimental group, compared to the control one, were assessed using analysis of variance (ANOVA). To avoid bias due to the variability between the experiments, the factor defining the different experimental groups was crossed with a second factor defining the different experiments (two-way ANOVA). $p$-values lower than 0.05 were considered statistically significant. Figures are representative from all experiments that were realized during the study.

\section{Results}

\subsection{Decreased Frequency of E. faecalis on Stool of CRC Patients}

The presence of $E$. faecalis was investigated in the feces of healthy donors (HD) and CRC patients (CC) (Table 1) through two complementary approaches. Firstly, we performed the isolation of E. faecalis from fresh stools, and we revealed its presence in four over nine HD, while only in two over nine CC. In detail, we isolated 12 colonies from four healthy donors and four colonies from two CRC patients (Table 3). MALDI-TOF analysis showed that five of the total 16 isolated colonies were not properly classified, being identified as E. faecium or E. galinarium and were discarded. The remaining 11 colonies were correctly identified as E. faecalis and were subjected to clonal analysis. Following the RAPD-PCR assay, eight different clonal profiles were identified: Six (EFH01-EFH06) from the four healthy donors and two from the two (CRC01 and CRC02) CC patients (Table 3).

In addition, to evaluate the overall prevalence of E. faecalis in the same subjects, including non-culturable strains, we performed a q-PCR analysis using the total DNA extracted from ultra-freeze stool samples (maximum two months of storage at $-80^{\circ} \mathrm{C}$ ). E. faecalis' presence was detected in seven over nine healthy donors (HD01, HD02, HD03, HD05, HD06, HD07, HD09), and only in two over nine CRC patients (CC6 and CC8). Taken together, the isolation and q-PCR approaches allowed us to detect the presence of E. faecalis in the stools of $77 \%$ of healthy donors and in $22 \%$ of CRC patients.

\subsection{Genotypic Characterization of E. faecalis' Strains}

The eight clonally different, representative, E. faecalis strains (Table 3) were genotyped by wholegenome-sequencing. First, we detected a different content of virulence genes (Supplementary Materials Table S1). Then, the clonal analysis by determination of the sequence type (ST) revealed that selected strains were part of E. faecalis lineages previously found to be associated with: (i) Clinical isolates (EFH04/ST209, EFH06/ST16, CRC01/ST40, and CRC02/ST59); (ii) the healthy gut (EFH01 and EFH05 both ST21); and (iii) sporadically detected or not characterized clones (EFH02/ST47 and EFH03) (Table 3 and Figure 1). Subsequently, these eight strains were used to produce a pre-fermented RPMI medium. 
Table 3. Isolated colonies of E. faecalis and characterized strains used for experimental protocols.

\begin{tabular}{|c|c|c|c|c|}
\hline & Donors & $\begin{array}{l}\text { E. faecalis/Total } \\
\text { Enterococci }\end{array}$ & $\begin{array}{c}\text { E. faecalis Strains } \\
\text { Used }\end{array}$ & ST \\
\hline \multirow{9}{*}{ CRC patients } & $\mathrm{CC} 1$ & $-/-$ & - & \\
\hline & $\mathrm{CC} 2$ & $-/-$ & - & \\
\hline & CC3 & $-/-$ & - & \\
\hline & $\mathrm{CC} 4$ & $-/-$ & - & \\
\hline & CC5 & $-/-$ & - & \\
\hline & CC6 & $2 / 3$ & CRC01 & 40 \\
\hline & CC7 & $-/-$ & - & \\
\hline & CC8 & $2 / 2$ & CRC02 & 59 \\
\hline & CC9 & $-/-$ & - & \\
\hline \multirow{11}{*}{ Healthy donors } & HD1 & $3 / 8$ & EFH01 & 21 \\
\hline & & & EFH02 & 47 \\
\hline & $\mathrm{HD} 2$ & $4 / 10$ & EFH05 & 21 * \\
\hline & & & EFH06 & 16 \\
\hline & HD3 & $3 / 8$ & EFH03 & unk \\
\hline & HD4 & $-/-$ & - & \\
\hline & HD5 & $-/ 4$ & - & \\
\hline & HD6 & $2 / 5$ & EFH04 & 209 \\
\hline & HD7 & $-/ 5$ & - & \\
\hline & HD8 & $-/ 3$ & - & \\
\hline & HD9 & $-/ 6$ & - & \\
\hline
\end{tabular}

E. faecalis: Enterococcus faecalis; CC: Colon Cancer; HD: Healthy donors; EFH: Enterococcus faecalis healthy ST: sequence type; * EFH01 and EFH05 are both classified as ST21, even if they display genotypic and functional differences.

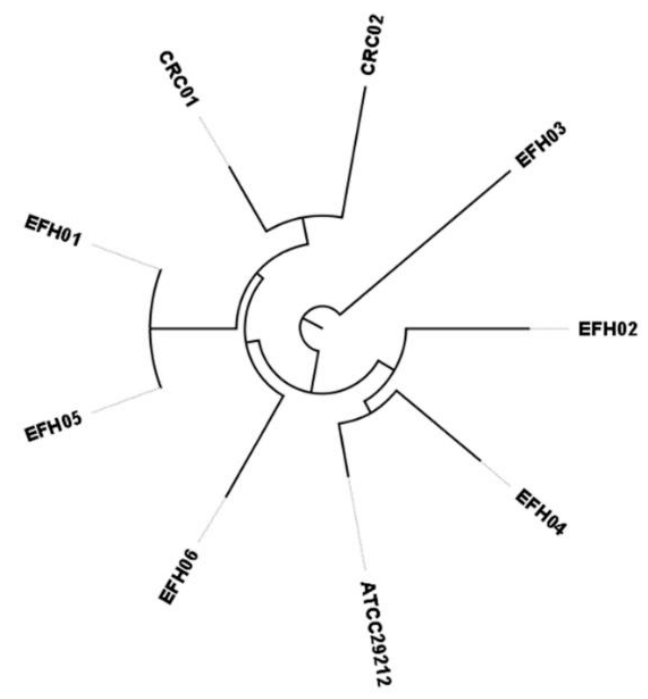

$\overline{0.05}$

Figure 1. Phylogenetic tree of isolated E. faecalis strains. The phylogenetic tree was generated using the ATCC 29212 genome (GenBank acc. no. NZ_CP008816.1) as a reference. CRC: colorectal cancer; EHF: Enterococcus faecalis healthy.

\subsection{Characterization of Secreted SCFAs}

Since LAB are known for their ability to produce SCFAs, we performed a quantitative analysis of a panel of SCFAs in pre-fermented medium samples obtained from all isolated E. faecalis strains (Table 4). As expected, acetic acid was the most significant SCFA produced by all strains, followed by 
iso-valeric acid. In addition, in all samples, we detected an SCFA not included in the panel of studied compounds. Taking into the account the retention time, distnace to iso-valeric acid, its fragmentation ions, and the relative abundances, we hypothesized the structure of 2-methyl-butyric acid. Since it is not included in the calibrated SCFAs, a quantitative evaluation was carried out using the calibration curve and reference ISTD of the iso-valeric acid. Data of the medium sample without fermentation of the studied strains did not show the presence of SCFAs, proving that they were produced by bacterial activities. Overall, we did not reveal substantial differences in the productions of SCFAs among all the isolated strains.

Table 4. Quantitative analyses of SCFAs in pre-fermented medium samples.

\begin{tabular}{cccccccc}
\hline Samples & $\begin{array}{c}\text { Acetic } \pm \\
\text { SD (ug/mL) }\end{array}$ & $\begin{array}{c}\text { Propionic } \\
\pm \text { SD } \\
\text { (ug/mL) }\end{array}$ & $\begin{array}{c}\text { Butyric } \pm \\
\text { SD } \\
\text { (ug/mL) }\end{array}$ & $\begin{array}{c}\text { Iso-Butyric } \\
\pm \text { SD } \\
\text { (ug/mL) }\end{array}$ & $\begin{array}{c}\text { Iso-Valeric } \\
\pm \text { SD } \\
\text { (ug/mL) }\end{array}$ & $\begin{array}{c}\text { 2-MethylButyric Valeric } \pm \\
\pm \text { SD } \\
\text { (ug/mL) }\end{array}$ & $\begin{array}{c}\text { SD } \\
\text { (ug/mL) }\end{array}$ \\
\hline RPMI & n.q. & n.q. & n.q. & n.q. & n.q. & n.q. & n.q. \\
EFH01 & $393.5 \pm 71.1$ & n.q. & n.q. & n.q. & $4.7 \pm 1.0$ & $4.2 \pm 0.8$ & n.q. \\
EFH02 & $268.7 \pm 19.7$ & $2.7 \pm 2.5$ & $4.2 \pm 1.1$ & n.q. & $3.3 \pm 0.4$ & $2.8 \pm 0.2$ & $0.3 \pm 0.6$ \\
EFH03 & $379.7 \pm 43.6$ & n.q & $2.1 \pm 1.8$ & n.q. & $3.3 \pm 0.5$ & $3.3 \pm 0.4$ & n.q. \\
EFH04 & $324.2 \pm 23.9$ & n.q & $1.0 \pm 1.7$ & n.q. & $4.8 \pm 0.2$ & $3.6 \pm 0.2$ & n.q. \\
EFH05 & $394.1 \pm 56.1$ & $0.8 \pm 1.4$ & $1.0 \pm 1.7$ & n.q. & $4.6 \pm 0.4$ & $4.1 \pm 0.4$ & n.q. \\
EFH06 & $381.2 \pm 16.1$ & n.q. & n.q. & n.q. & $6.4 \pm 0.5$ & $6.1 \pm 0.6$ & n.q. \\
CRC01 & $417.5 \pm 89.3$ & $1.2 \pm 2.1$ & $2.6 \pm 2.3$ & n.q. & $4.2 \pm 0.9$ & $4.0 \pm 0.8$ & n.q. \\
CRC02 & $399.7 \pm 44.5$ & n.q. & $3.3 \pm 0.1$ & n.q. & $3.7 \pm 1.1$ & $2.4 \pm 0.4$ & n.q. \\
ATCC & $380.6 \pm 45.9$ & n.q. & n.q. & n.q. & $4.7 \pm 0.8$ & $3.5 \pm 0.6$ & n.q. \\
\hline
\end{tabular}

n.q.: below limit of detection of the quantitative method. Data are presented as mean \pm SD (standard deviation).

SCFAs: Short chain fatty acids; RPMI: Roswell Park Memorial Institute medium.

\subsection{From the Isolated Strains, Three were Able to Decrease Tumor Cell Growth}

MTT assays were made at 24, 48, and $72 \mathrm{~h}$ of HCT-8, HCT-116, SW-620, and CRL-1790 cells' exposure to the pre-fermented medium with E. faecalis strains. In the preliminary experiments, we observed effects over the cell viability/proliferation after only $72 \mathrm{~h}$, without differences regarding the control after 24 and $48 \mathrm{~h}$ (data not shown). Therefore, all the following experiments were performed at $72 \mathrm{~h}$ of pre-fermented medium exposure. The results revealed that secreted metabolites from the strains EFH01, EFH02, EFH03, and EFH04 (all from healthy donors) reduced the viability/proliferation of HCT-8 cells; similar results were also obtained with HCT-116 cells (except for EFH04), while no effect resulted in the SW-620 cell line (Figure 2). Secreted metabolites from EFH05, EFH06, CRC01, and $\mathrm{CRC} 02$ strains did not elicit any significant effects in the three CRC cell lines. Aiming to evaluate the potential effect of strains' metabolites on normal cells, we used the embryo colonic cell line, CLR-1790. Noteworthy, we observed that E. faecalis strains' metabolites did not significantly interfere with the viability/proliferation of these cells.

To better clarify the extent to which E. faecalis secreted metabolites affect cell proliferation, we employed Ki67 immunofluorescence staining as an accurate measurement of cellular proliferation (Figure 3). We observed that the Ki67 expression was decreased only on HCT-8 and HCT-116 cell lines cultured with the metabolites of the EFH01, EFH02, EFH03, and EFH04 strains, corroborating the results of the MTT assays (Figure 4). Finally, in agreement with the MTT assay, a complementary cell cycle phase distribution assay demonstrated a trend to decreasing G0/G1 and increasing S phases, mainly with the metabolites of the EFH03 strain (Supplementary Materials, Figure S1). 

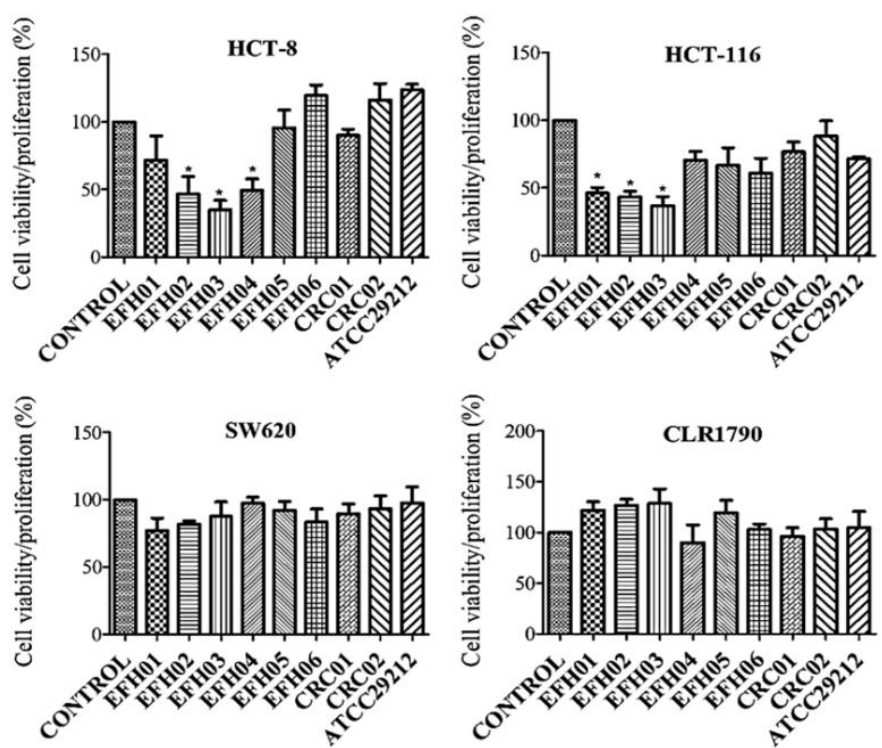

Figure 2. Estimated differences in the cell viability/proliferation index for each experimental group with respect to the control, one net of variability between the experiments after $72 \mathrm{~h}$ of exposure to E. faecalis metabolites. Error bars indicate the standard deviation $\left({ }^{*} p \leq 0.05\right)$. HCT-8: Human ileocecal adenocarcinoma cell line; HCT-116: Human colon carcinoma cell line; SW-620: human colorectal adenocarcinoma cell line; CLR-1790: normal human diploid cell line

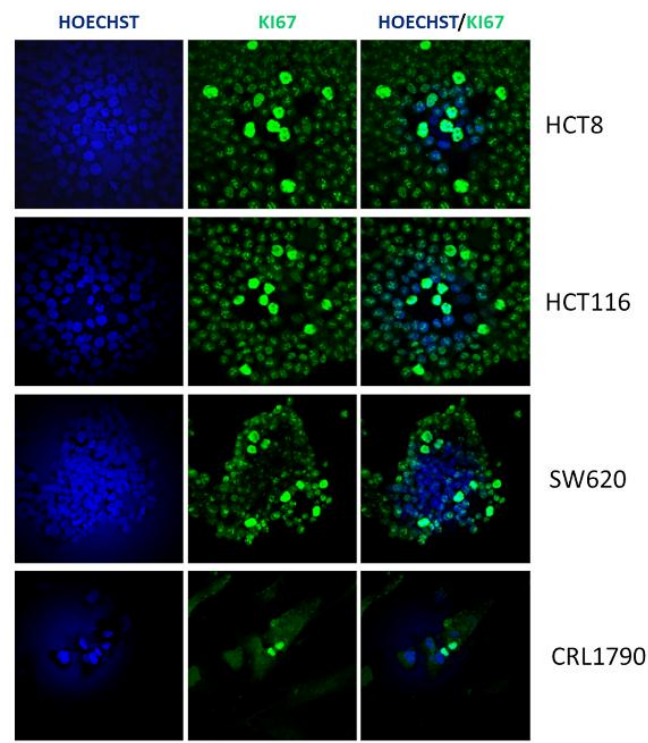

Figure 3. Representative double-labeled immunofluorescence images for Ki67 (green) and Hoechst (blue) in HCT8, HCT116, and SW620 CRC cells, and embryo colonic CLR1790 cells after $72 \mathrm{~h}$ of culture. 

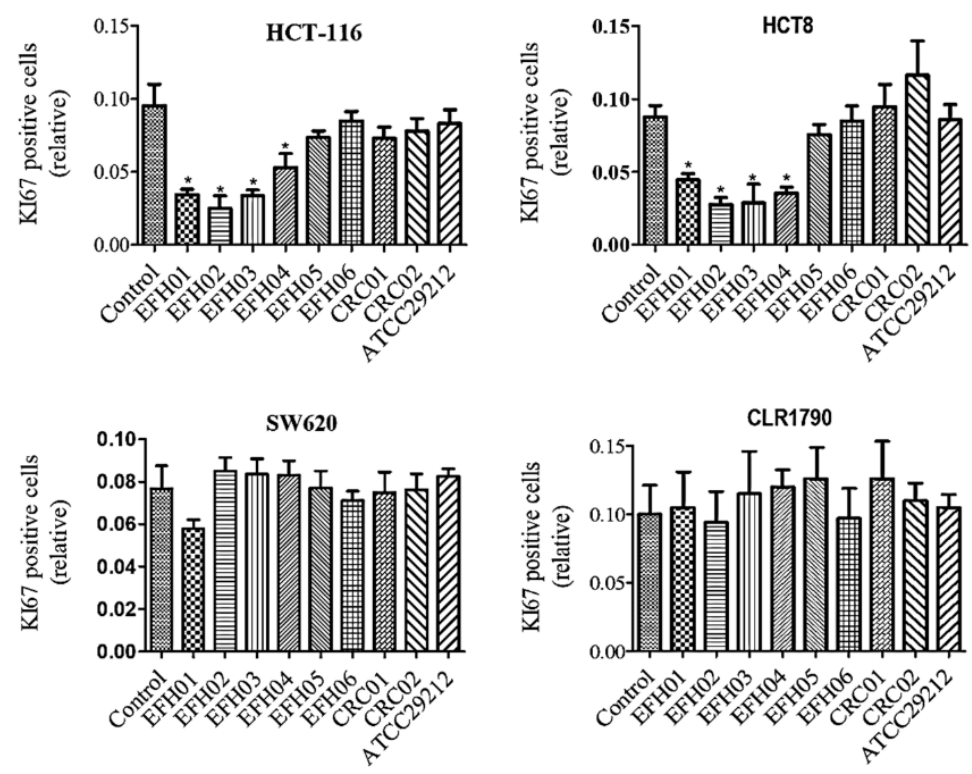

Figure 4. Ki67 positive HCT8, HCT116, SW620, and CLR1790 cells after $72 \mathrm{~h}$ of exposure to the metabolites produced from different strains of E. faecalis. Error bars indicate the standard deviation $\left({ }^{*} p \leq 0.05\right)$.

\section{Discussion}

In this study, aiming to investigate the potential role of E. faecalis in CRC development, we compared the effect of E. faecalis strains isolated from CRC patients' and healthy subjects' stools on the viability/proliferation of different colorectal cells lines. Actually, gut microbes can regulate the colonic epithelial cells' homeostasis (proliferation, differentiation, and apoptosis) and GM dysbiosis has been widely associated with CRC development [12-14]. In addition, metagenome-wide association studies on fecal samples have characterized numerous microbial markers of CRC [40,41]. Some authors documented a higher abundance of E. faecalis in CRC tumor and adjacent tissue [42], as well as in stool samples of CRCpatients [23,43], as compared to healthy subjects. However, in our cohort of patients, we did not confirm these previous findings. In detail, only two out of the nine CRC patients had cultivable E. faecalis in stool samples, while in healthy donors, we detected strains in seven out of the nine donors. In former studies [24,44], the authors used only a PCR-based experimental approach that did not unequivocally distinguish E. faecalis from other Enterococci. Conversely, we used a primer pair with a higher specificity to evaluate the presence of $E$. faecalis. So, a direct comparison among our data with previous ones is affected by this procedural bias. Although our observations were restricted to a limited number of subjects, the remarkable differences disclosed between CRC patients and healthy donors suggest that the majority of CRC patients possibly lose the physiological stool presence of E. faecalis that we supposed to have a protective role on gut health.

In support of our hypothesis, recent studies demonstrated that E. faecalis can affect the phosphorylation status of the peroxisome proliferator-activated receptor (PPAR) $\gamma$, triggering the activation of its downstream pathways [27]. PPAR $\gamma$ acts as a growth-limiting and pro-differentiating transcription factor in colonic epithelial cells [44] and contributes to innate antimicrobial immunity in the colon [45]. Deregulation of the PPAR $\gamma$ axis in CRC progression has been described [44] and efforts aimed to identify PPAR $\gamma$ agonists as anti-neoplastic agents are ongoing. Therefore, the disappearance of E. faecalis might reduce (or remove) the presence of a PPAR $\gamma$ modulator, thus contributing to a pro-tumoral milieu. It will be of interest to focus future studies on the definition of the precise phase of E. faecalis disappearance in the feces, during CRC progression.

Aiming to understand whether genetic differences documented by whole-genome-sequencing involve variation in the fermentation processes and their final products, we analyzed the concentrations of SCFAs on the culture supernatant of all isolated E. faecalis strains. SCFAs are physiologically active 
products, primarily obtained by the fermentation of soluble dietary fiber and resistant starch by commensal bacteria in the colon [46]. SCFAs can profoundly affect the inflammatory response $[47,48]$, being closely linked to decreased CRC incidence [49], and also the adaptive immune response [50] (which has a key role in CRC progression, as we have previously demonstrated [16]). The in vitro assay demonstrated that SCFAs are able to inhibit the proliferation [51] of CRC cell lines by inducing their apoptosis [52]. The most frequent SCFAs in the colon and stool samples are acetic, propionic, and butyric acids, which are present in an approximate molar ratio of 60:20:20 [53,54].

SCFAs, especially those mentioned, are one of the most important products of the fermentation process and present diverse beneficial properties to human health, such as regulation of metabolism, inflammation, and disease (reviewed by Tan et al.) [55]. We did not observe significant differences in the SCFA concentrations among the isolated strains; however, the presence of 2-methyl-butyric acid, which was produced by all strains, was interesting, since this volatile organic compound can be used for discriminate analysis in the diagnosis of gastrointestinal diseases [56]. Therefore, its inclusion in the SCFAs' panel for future studies could improve the correlation between the analytical data and biological evidence.

Bearing in mind the controversial role of E. faecalis in CRC development ${ }^{6}$ and the different behaviour of CRC cell lines in response to external stimuli (as well as each tumor having its own genotype, origin, and proliferative index [57]), we compared the effect of each isolated strain's fermented products on the proliferation of three tumor cell lines: HCT-8 and HCT-116 and SW620s. As a result, we documented an antiproliferative effect of four (to note, all isolated from the healthy donors) of the eight isolated strains on HCT- 8 and HCT-116 cells, while the others (two from CRC patients and two isolated from the HD02 subject) had no effect. In addition, we did not reveal any significant anti-proliferative effects in SW-620 cells, a very important result, on normal colonic CRL-1790 cells. Therefore, we disclosed a heterogeneous scenario, where only some E. faecalis strains derived from healthy donors possess inhibitory effects on primitive tumor-derived CRC cells' viability/proliferation. Coherent with observation of a severe reduction of E. faecalis presence in the feces of CRC patients, the isolated strains did not show any anti-tumoral effect.

The differential ability of the isolated strains to impact colon cancer cells' viability/proliferation, although perhaps not due to differences in SCFAs' production, could depend on the production of numerous other metabolites (that we aim to investigate in future studies). For example, the GM products of various polyphenols' metabolism (such as urolithins, benzoic acid, and 3-phenypropionic acid) are capable of inhibiting the proliferation of different human colon cancer cell lines [58,59]. In addition, isothiocyanates, the hydrolysis products of glucosinolates of various bacterial species, including E. faecalis [60], have been shown to have anti-carcinogenic properties in both in vivo and in vitro studies, causing cell cycle arrest and inducing apoptosis [61].

Overall, the obtained results lay the groundwork for a more in-depth characterization of the crosstalk between E. faecalis and CRC development, which is based not only on the evaluation of its presence in feces, but also looks at the biology of each different strain.

In conclusion, we demonstrated, for the first time, that some E. faecalis strains may have anti-tumoral properties and, in addition, different strains could have a highly heterogeneous content of virulence factors [62,63] (Supplementary Materials). Therefore, in future investigations, we suggest the specific lineages of E. faecalis are investigate to clarify their role in both healthy hosts and in gut inflammation.

Finally, we suggest that E. faecalis strains with a probable protective role, such as EFH01, EFH02, and EFH03, should be investigated in order to be used as a potential probiotic treatment of pre-CRC intestinal disorders (e.g., inflammatory bowel disease (IBD) and adenoma) to prevent disease progression. 
Supplementary Materials: The following are available online at http:/ www.mdpi.com/2077-0383/8/3/388/s1, Figure S1: Cell cycle phase distribution of CLR1790 and HCT-116 cell lines after $48 \mathrm{~h}$ of bacterial metabolites exposure., Table S1: Genotypic characterization of the virulence factors of the different E. faecalis strains, Table S2: Ionic signal used for quali/quantitation and relative ISTD of each SCFA acquired by the GC-MS method.

Author Contributions: C.V.D.A., A.A. designed the research; E.R., E.N. and R.B. collected the samples and patients data; C.V.D.A., M.L., V.d.P. performed the experiments and analyzed the data; S.B., G.B. and M.M. performed all GC-MS analysis of SCFAs; C.V.D.A., M.L. and V.d.P. wrote the paper; A.A., A.T., G.M.R., D.P. and N.S. supervised all the experimental work and revised the manuscript; all authors critically read and approved the manuscript.

Funding: The research has been founded with a grant from the regional contribution of "The Programma Attuativo Regionale (Toscana)" funded by FAS (now FSC)-MICpROBIMM, the Italian Ministry of University and Research (MIUR) and the Foundation 'Ente Cassa di Risparmio di Firenze'.

Acknowledgments: The authors thank all the CRC patients enrolled with the Unit of Surgery, University Hospital of Careggi (AOUC), University of Florence, and the healthy controls. The authors thank Federico Boem for the valuable help in revising the manuscript, Alessandro Magrini for the statistical analysis, and Elisabetta Rovida for technical assistance on FACS analysis. We are also very grateful to the referees for their comments and suggestions in improving the manuscript.

Conflicts of Interest: The authors declare no conflict of interest.

\section{References}

1. Siegel, R.L.; Miller, K.D.; Jemal, A. Cancer Statistics, 2018. CA Cancer J. Clin. 2018, 68, 7-30. [CrossRef]

2. Das Neves, F.J.; Mattos, I.E.; Koifman, R.J. Colon and rectal cancer mortality in Brazilian capitals, 1980-1997. Arq. Gastroenterol. 2005, 42, 63-70.

3. Ferlay, J.; Shin, H.; Bray, F.; Forman, D.; Mathers, C.; Parkin, D.M. Estimates of worldwide burden of cancer in 2008: GLOBOCAN 2008. Int. J. Cancer. 2010, 127, 2893-2917. [CrossRef]

4. MacFarlane, A.J.; Stover, P.J. Convergence of genetic, nutritional and inflammatory factors in gastrointestinal cancers. Nutr. Rev. 2007, 65, S157-S166. [CrossRef]

5. Colorectal Cancer Risk Factors. 2019. Available online: http://www.cdc.gov/cancer/colorectal/basic_info/ risk_factors.htm (accessed on 7 February 2019).

6. De Almeida, C.V.; Taddei, A.; Amedei, A. The controversial role of Enterococcus faecalis in Colorectal cancer. Therap. Adv. Gastroenterol. 2018, 11, 1-11. [CrossRef]

7. Rea, D.; Coppola, G.; Palma, G.; Barbieri, A.; Luciano, A.; Del Prete, P.; Rossetti, S.; Berretta, M.; Facchini, G.; Perdonà, S.; et al. Microbiota effects on cancer: From risks to therapies. Oncotarget 2018, 9, 17915-17927. [CrossRef]

8. Boleij, A.; Tjalsma, H. Gut bacteria in health and disease: A survey on the interface between intestinal microbiology and colorectal cancer. Biol. Rev. Camb. Philos. Soc. 2012, 87, 701-730. [CrossRef]

9. Umesaki, Y.; Okada, Y.; Matsumoto, S.; Imaoka, A.; Setoyama, H. Segmented filamentous bacteria are indigenous intestinal bacteria that activate intraepithelial lymphocytes and induce MHC class II molecules and fucosylasialo GM1 glycolipids on the small intestinal epithelial cells in the ex-germ-free mouse. Microbiol. Immunol. 1995, 39, 555-562. [CrossRef]

10. Zur Hausen, H. The search for infectious causes of human cancers: Where and why. Virology 2009, 392, 1-10. [CrossRef]

11. Davis, C.D.; Milner, J.A. Gastrointestinal microflora, food components and colon cancer prevention. J. Nutr. Biochem. 2009, 20, 743-752. [CrossRef]

12. Collins, D.; Hogan, A.M.; Winter, D.C. Microbial and viral pathogens in colorectal cancer. Lancet Oncol. 2011, 12, 504-512. [CrossRef]

13. Russo, E.; Bacci, G.; Chiellini, C.; Fagorzi, C.; Niccolai, E.; Taddei, A.; Ricci, F.; Ringressi, M.N.; Borrelli, R.; Melli, F.; et al. Preliminary Comparison of Oral and Intestinal Human Microbiota in Patients with Colorectal Cancer: A Pilot Study. Front. Microbiol. 2018, 8, 2699. [CrossRef] [PubMed]

14. Russo, E.; Taddei, A.; Ringressi, M.N.; Ricci, F.; Amedei, A. The interplay between the microbiome and the adaptive immune response in cancer development. Therap. Adv. Gastroenterol. 2016, 9, 594-605. [CrossRef] [PubMed]

15. Artis, D. Epithelial-cell recognition of commensal bacteria and maintenance of immune homeostasis in the gut. Nat. Rev. Immunol. 2008, 8, 411-420. [CrossRef] 
16. Niccolai, E.; Ricci, F.; Russo, E.; Nannini, G.; Emmi, G.; Taddei, A.; Ringressi, M.N.; Melli, F.; Miloeva, M.; Cianchi, F.; et al. The Different Functional Distribution of "Not Effector" T Cells (Treg/Tnull) in Colorectal Cancer. Front Immunol. 2017, 8, 1900. [CrossRef] [PubMed]

17. Zou, S.; Fang, L.; Lee, M.H. Dysbiosis of gut microbiota in promoting the development of colorectal cancer. Gastroenterol. Rep. (Oxf). 2018, 6, 1-12. [CrossRef]

18. Prakash, S.; Rodes, L.; Coussa-Charley, M.; Tomaro-Duchesneau, C. Gut microbiota: Next frontier in understanding human health and development of biotherapeutics. Biologics 2011, 5, 71-86. [PubMed]

19. Habermann, W.; Zimmermann, K.; Skabaris, H.; Kunze, R.; Rusch, V. The effect of bacterial immunostimulant (human Enterococcus faecalis bacteria) on the occurrence of relapse in patients with chronic bronchitis. Arzneimittel-Forschung. 2001, 51, 931-937.

20. Chen, C.C.; Kong, M.S.; Lai, M.W.; Chao, H.C.; Chang, K.W.; Chen, S.Y.; Huang, Y.C.; Chiu, C.H.; Li, W.C.; Lin, P.Y.; et al. Probiotics have clinical, microbiological, and immunologic efficacy in acute infectious diarrhea. J. Pediatr. Infect. Dis 2010, 29, 135-138. [CrossRef]

21. Martinez, R.C.; Bedani, R.; Saad, S.M. Scientific evidence for health effects attributed to the consumption of probiotics and prebiotics: An update for current perspectives and future challenges. Br. J. Nutr. 2015, 114, 1993-2015. [CrossRef]

22. Huycke, M.M.; Abrams, V.; Moore, D.R. Enterococcus faecalis produces extracellular superoxide and hydrogen peroxide that damages colonic epithelial cell DNA. Carcinogenesis 2002, 23, 529-536. [CrossRef]

23. Balamurugan, R.; Rajendiran, E.; George, S.; Samuel, G.V.; Ramakrishna, B.S. Real-time polymerase chain reaction quantification of specific butyrate-producing bacteria, Desulfovibrio and Enterococcus faecalis in the feces of patients with colorectal cancer. J. Gastroenterol. Hepatol. 2008, 23, 1298-1303. [CrossRef]

24. Pericàs, J.M.; Corredoira, J.; Moreno, A.; García-País, M.J.; Falces, C.; Rabuñal, R.; Mestres, C.A.; Alonso, M.P.; Marco, F.; Quintana, E.; et al. Relationship between Enterococcus faecalis infective endocarditis and colorectal neoplasm: Preliminary results from a Cohort of 154 patients. Rev. Esp. Cardiol. 2017, 70, 451-458. [CrossRef]

25. Hill, M.J.; Drasar, B.S.; Aries, V.; Aries, V.; Crowther, J.S.; Williams, R.E. Bacteria and aetiology of cancer of large bowel. Lancet 1971, 1, 95-100. [CrossRef]

26. Fanaro, S.; Chierici, R.; Guerrini, P.; Vigi, V. Intestinal microflora in early infancy: Composition and development. Acta Paediatr. Suppl. 2003, 91, 48-55. [CrossRef]

27. Are, A.; Aronsson, L.; Wang, S.; Greicius, G.; Lee, Y.K.; Gustafsson, J.A.; Pettersson, S.; Arulampalam, V. Enterococcus faecalis from newborn babies regulate endogenous PPARgamma activity and IL-10 levels in colonic epithelial cells. Proc. Natl. Acad. Sci. USA 2008, 105, 1943-1948. [CrossRef]

28. Wang, S.; Hibberd, M.L.; Pettersson, S.; Lee, Y.K. Enterococcus faecalis from healthy infants modulates inflammation through MAPK signaling pathways. PLoS ONE 2014, 9, e97523. [CrossRef]

29. Martin, B.; Garriga, M.; Hugas, M.; Aymerich, T. Genetic diversity and safety aspects of enterococci from slightly fermented sausages. J Appl Microbiol. 2005, 98, 1177-1190. [CrossRef]

30. Sedgley, C.M.; Nagel, A.C.; Shelburne, C.E.; Clewell, D.B.; Appelbe, O.; Molander, A. Quantitative real-time PCR detection of oral Enterococcus faecalis in humans. Arch. Oral. Biol. 2005, 50, 575-583. [CrossRef]

31. Giani, T.; Arena, F.; Pollini, S.; Di Pilato, V.; D’Andrea, M.M.; Henrici De Angelis, L.; Bassetti, M.; Rossolini, G.M. Pseudomonas aeruginosa Working Group. Italian nationwide survey on Pseudomonas aeruginosa from invasive infections: Activity of ceftolozane/tazobactam and comparators, and molecular epidemiology of carbapenemase producers. J. Antimicrob. Chemother. 2017, 3, 664-671.

32. Center for Genomic Epidemiology. Available online: https://cge.cbs.dtu.dk/services/MLST/ (accessed on 19 March 2019).

33. Center for Genomic Epidemiology. Available online: https://cge.cbs.dtu.dk/services/CSIPhylogeny (accessed on 19 March 2019).

34. Arndt, D.; Grant, J.R.; Marcu, A.; Sajed, T.; Pon, A.; Liang, Y.; Wishart, D.S. PHASTER: A better, faster version of the PHAST phage search tool. Nucleic Acids Res. 2016, 44, W16-W21. [CrossRef] [PubMed]

35. Center for Genomic Epidemiology. Available online: https://cge.cbs.dtu.dk/services/ (accessed on 19 March 2019).

36. Basic Local Alignment Search Tool. Available online: http://blast.ncbi.nlm.nih.gov/ (accessed on 19 March 2019).

37. Grootaert, C.; Van de Wiele, T.; Van Roosbroeck, I.; Possemiers, S.; Vercoutter-Edouart, A.S.; Verstraete, W.; Bracke, M.; Vanhoecke, B. Bacterial monocultures, propionate, butyrate and $\mathrm{H}_{2} \mathrm{O}_{2}$ modulate the expression, 
secretion and structure of the fasting-induced adipose factor in gut epithelial cell lines. Environ. Microbiol. 2011, 13, 1778-1789. [CrossRef] [PubMed]

38. Mosmann, T. Rapid colorimetric assay for cellular growth and survival: Application to proliferation and cytotoxicity assays. J. Immunol. Methods 1983, 16, 55-63. [CrossRef]

39. Wayne Rasband. NationalInstitutes of Health, Bethesda. Available online: http://rsbweb.nih.gov/ij/index. html (accessed on 19 March 2019).

40. Yu, J.; Feng, Q.; Wong, S.H.; Zhang, D.; Liang, Q.Y.; Qin, Y.; Tang, L.; Zhao, H.; Stenvang, J.; Li, Y.; et al. Metagenomic analysis of faecal microbiome as a tool towards targeted non-invasive biomarkers for colorectal cancer. Gut 2017, 66, 70-78. [CrossRef] [PubMed]

41. Feng, Q.; Liang, S.; Jia, H.; Stadlmayr, A.; Tang, L.; Lan, Z.; Zhang, D.; Xia, H.; Xu, X.; Jie, Z.; et al. Gut microbiome development along the colorectal adenoma-carcinoma sequence. Nat Commun. 2015, 6, 6528. [CrossRef]

42. Zhou, Y.; He, H.; Xu, H.; Li, Y.; Li, Z.; Du, Y.; He, J.; Zhou, Y.; Wang, H.; Nie, Y. Association of oncogenic bacteria with colorectal cancer in South China. Oncotarget 2016, 7, 80794-80802. [CrossRef]

43. Wang, T.; Cai, G.; Qiu, Y.; Fei, N.; Zhang, M.; Pang, X.; Jia, W.; Cai, S.; Zhao, L. Structural segregation of gut microbiota between colorectal cancer patients and healthy volunteers. ISME J. 2012, 6, 320-329. [CrossRef] [PubMed]

44. Sabatino, L.; Pancione, M.; Votino, C.; Colangelo, T.; Lupo, A.; Novellino, E.; Lavecchia, A.; Colantuoni, V. Emerging role of the $\beta$-catenin-PPAR $\gamma$ axis in the pathogenesis of colorectal cancer. World J. Gastroenterol. 2014, 20, 7137-7151. [CrossRef] [PubMed]

45. Peyrin-Biroulet, L.; Beisner, J.; Wang, G.; Nuding, S.; Oommen, S.T.; Kelly, D.; Parmentier-Decrucq, E.; Dessein, R.; Merour, E.; Chavatte, P.; et al. Peroxisome proliferator-activated receptor gamma activation is required for maintenance of innate antimicrobial immunity in the colon. Proc. Natl. Acad. Sci. USA 2010, 107, 8772-8777. [CrossRef]

46. den Besten, G.; van Eunen, K.; Groen, A.K.; Venema, K.; Reijngoud, D.-J.; Bakker, B.M. The role of short-chain fatty acids in the interplay between diet, gut microbiota, and host energy metabolism. J. Lipid Res. 2013, 54, 2325-2340. [CrossRef]

47. McLoughlin, R.F.; Berthon, B.S.; Jensen, M.E.; Baines, K.J.; Wood, L.G. Short-chain fatty acids, prebiotics, synbiotics, and systemic inflammation: A systematic review and meta-analysis. Am. J. Clin. Nutr. 2017, 106, 930-945. [CrossRef] [PubMed]

48. Le Poul, E.; Loison, C.; Struyf, S.; Springael, J.Y.; Lannoy, V.; Decobecq, M.E.; Brezillon, S.; Dupriez, V.; Vassart, G.; Van Damme, J.; et al. Functional characterization of human receptors for short chain fatty acids and their role in polymorphonuclear cell activation. J. Biol. Chem. 2003, 278, 25481-25489. [CrossRef] [PubMed]

49. Wong, J.M.; de Souza, R.; Kendall, C.W.; Emam, A.; Jenkins, D.J. Colonic health: Fermentation and short chain fatty acids. J. Clin. Gastroenterol. 2006, 40, 235-243. [CrossRef] [PubMed]

50. Kespohl, M.; Vachharajani, N.; Luu, M.; Harb, H.; Pautz, S.; Wolff, S.; Sillner, N.; Walker, A.; Schmitt-Kopplin, P.; Boettger, T.; et al. The Microbial Metabolite Butyrate Induces Expression of Th1-Associated Factors in CD4+ T Cells. Front. Immunol. 2017, 8, 1036. [CrossRef] [PubMed]

51. Thirabunyanon, M.; Hongwittayakorn, P. Potential probiotic lactic acid bacteria of human origin induce antiproliferation of colon cancer cells via synergic actions in adhesion to cancer cells and short-chain fatty acid bioproduction. Appl. Biochem. Biotechnol. 2013, 169, 511-525. [CrossRef]

52. Velayos, F.S.; Liu, L.; Lewis, J.D.; Allison, J.E.; Flowers, N.; Hutfless, S.; Abramson, O.; Perry, G.S.; Herrinton, L.J. Prevalence of colorectal cancer surveillance for ulcerative colitis in an integrated health care delivery system. Gastroenterology 2010, 139, 1511-1518. [CrossRef]

53. Hijova, E.; Chmelarova, A. Short chain fatty acids and colonic health. Bratisl. Lek. Listy. 2007, 108, $354-358$.

54. Cummings, J.H.; Pomare, E.W.; Branch, W.J.; Naylor, C.P.; Macfarlane, G.T. Short chain fatty acids in human large intestine, portal, hepatic and venous blood. Gut 1987, 28, 1221-1227. [CrossRef]

55. Tan, J.; McKenzie, C.; Potamitis, M.; Thorburn, A.N.; Mackay, C.R.; Macia, L. The role of short-chain fatty acids in health and disease. Adv. Immunol. 2014, 121, 91-119.

56. Garner, C.E.; Smith, S.; de Lacy Costello, B.; White, P.; Spencer, R.; Probert, C.S.; Ratcliffe, N.M. Volatile organic compounds from feces and their potential for diagnosis of gastrointestinal disease. FASEB J. 2007, 21, 1675-1688. [CrossRef] 
57. Singh, M.P.; Rai, S.; Suyal, S.; Singh, S.K.; Singh, N.K.; Agarwal, A.; Srivastava, S. Genetic and epigenetic markers in colorectal cancer screening: Recent advances. Expert Rev. Mol. Diagn. 2017, 17, 665-685. [CrossRef] [PubMed]

58. González-Sarrías, A.; Giménez-Bastida, J.A.; Núñez-Sánchez, M.Á.; Larrosa, M.; García-Conesa, M.T.; Tomás-Barberán, F.A.; Espín, J.C. Phase-II metabolism limits the antiproliferative activity of urolithins in human colon cancer cells. Eur. J. Nutr. 2014, 53, 853-864. [CrossRef] [PubMed]

59. Sadeghi, E.S.; Li, X.Q.; Ghorbani, M.; Azadi, B.; Kubow, S. Chlorogenic Acid and Its Microbial Metabolites Exert Anti-Proliferative Effects, S-Phase Cell-Cycle Arrest and Apoptosis in Human Colon Cancer Caco-2 Cells. Int. J. Mol. Sci. 2018, 19, 723. [CrossRef] [PubMed]

60. Hullar, M.A.; Burnett-Hartman, A.N.; Lampe, J.W. Gut microbes, diet, and cancer. Cancer Treat Res. 2014, 159, 377-399.

61. Myzak, M.C.; Hardin, K.; Yan, M.; Tong, P.; Dashwood, R.; Ho, E. Sulforaphane inhibits HDAC activity in prostate cancer cells, retards growth of PC3 xenografts, and inhibits HDAC activity in vivo. FASEB J. 2006, 20, A150.

62. Archimbaud, C.; Shankar, N.; Forestier, C.; Baghdayan, A.; Gilmore, M.S.; Charbonné, F.; Joly, B. In vitro adhesive properties and virulence factors of Enterococcus faecalisstrains. Res. Microbiol. 2002, 153, 75-80. [CrossRef]

63. Creti, R.; Imperi, M.; Bertuccini, L.; Fabretti, F.; Orefici, G.; Di Rosa, R.; Baldassarri, L. Survey for virulence determinants among Enterococcus faecalis isolated from different sources. J. Med. Microbiol. 2004, 53, 13-20. [CrossRef] [PubMed]

(C) 2019 by the authors. Licensee MDPI, Basel, Switzerland. This article is an open access article distributed under the terms and conditions of the Creative Commons Attribution (CC BY) license (http:/ / creativecommons.org/licenses/by/4.0/). 